J. Dairy Sci. 99:7247-7260

http://dx.doi.org/10.3168/jds.2015-10646

(C) 2016, THE AUTHORS. Published by FASS and Elsevier Inc. on behalf

of the American Dairy Science Association ${ }^{\circledR}$. This is an open access article under

the CC BY-NC-ND license (http://creativecommons.org/licenses/by-nc-nd/3.0/).

\title{
Changes throughout lactation in phenotypic and genetic correlations between methane emissions and milk fatty acid contents predicted from milk mid-infrared spectra
}

\author{
M.-L. Vanrobays,${ }^{* 1}$ C. Bastin, ${ }^{*}$ J. Vandenplas, ${ }^{*} \dagger^{2}$ H. Hammami, ${ }^{*}$ H. Soyeurt, ${ }^{*}$ A. Vanlierde, $\ddagger$ F. Dehareng, $\ddagger$ \\ E. Froidmont, $\S$ and N. Gengler* \\ ${ }^{*}$ Agriculture, Bio-engineering and Chemistry Department, Gembloux Agro-Bio Tech, University of Liège, B-5030 Gembloux, Belgium \\ †National Fund for Scientific Research, B-1000 Brussels, Belgium \\ fWalloon Agricultural Research Centre, Valorization of Agricultural Products, B-5030 Gembloux, Belgium \\ $\S$ Walloon Agricultural Research Centre, Production and Sectors Department, B-5030 Gembloux, Belgium
}

\begin{abstract}
The aim of this study was to estimate phenotypic and genetic correlations between methane production $(\mathrm{Mp})$ and milk fatty acid contents of first-parity Walloon Holstein cows throughout lactation. Calibration equations predicting daily $\mathrm{Mp}(\mathrm{g} / \mathrm{d})$ and milk fatty acid contents (g/100 dL of milk) were applied on milk midinfrared spectra related to Walloon milk recording. A total of 241,236 predictions of Mp and milk fatty acids were used. These data were collected between 5 and 305 d in milk in 33,555 first-parity Holstein cows from 626 herds. Pedigree data included 109,975 animals. Bivariate (i.e., $\mathrm{Mp}$ and a fatty acid trait) random regression test-day models were developed to estimate phenotypic and genetic parameters of $\mathrm{Mp}$ and milk fatty acids. Individual short-chain fatty acids (SCFA) and groups of saturated fatty acids, SCFA, and medium-chain fatty acids showed positive phenotypic and genetic correlations with $\mathrm{Mp}$ (from 0.10 to 0.16 and from 0.23 to 0.30 for phenotypic and genetic correlations, respectively), whereas individual long-chain fatty acids (LCFA), and groups of LCFA, monounsaturated fatty acids, and unsaturated fatty acids showed null to positive phenotypic and genetic correlations with Mp (from -0.03 to 0.13 and from -0.02 to 0.32 for phenotypic and genetic correlations, respectively). However, these correlations changed throughout lactation. First, de novo individual and group fatty acids (i.e., C4:0, C6:0, C8:0, C10:0, C12:0, C14:0, SCFA group) showed low phenotypic or
\end{abstract}

\footnotetext{
Received November 16, 2015.

Accepted May 22, 2016.

${ }^{1}$ Corresponding author: mlvanrobays@student.ulg.ac.be

${ }^{2}$ Current address: Animal Breeding and Genomics Centre, Wageningen UR Livestock Research, 6700 AH Wageningen, the Netherlands.
}

genetic correlations (or both) in early lactation and higher at the end of lactation. In contrast, phenotypic and genetic correlations between $\mathrm{Mp}$ and C16:0, which could be de novo synthetized or derived from blood lipids, were more stable during lactation. This fatty acid is the most abundant fatty acid of the saturated fatty acid and medium-chain fatty acid groups of which correlations with Mp showed the same pattern across lactation. Phenotypic and genetic correlations between $\mathrm{Mp}$ and C17:0 and C18:0 were low in early lactation and increased afterward. Phenotypic and genetic correlations between $\mathrm{Mp}$ and $\mathrm{C} 18: 1$ cis-9 originating from the blood lipids were negative in early lactation and increased afterward to become null from 18 wk until the end of lactation. Correlations between $\mathrm{Mp}$ and groups of LCFA, monounsaturated fatty acids, and unsaturated fatty acids showed a similar or intermediate pattern across lactation compared with fatty acids that compose them. Finally, these results indicate that correlations between $\mathrm{Mp}$ and milk fatty acids vary following lactation stage of the cow, a fact still often ignored when trying to predict Mp from milk fatty acid profile. Key words: fatty acid, methane, dairy cattle, midinfrared

\section{INTRODUCTION}

Greenhouse gases are large contributors to climate change (e.g., IPCC, 2006). Methane from gastro-enteric fermentation is the major greenhouse gases produced by dairy cattle (Gerber et al., 2013). Moreover, methane production ( $\mathbf{M p}$; i.e., in $\mathrm{g} / \mathrm{d}$ ) implies loss of gross energy intake (from 2 to $12 \%$ of gross energy intake; Johnson and Johnson, 1995). Therefore, efforts to mitigate methane emissions are needed to improve the environmental sustainability and economic profitability of dairy production. 
In cattle, gastro-enteric fermentation of glucose equivalents from starch or plant cell wall polymers occurs in the rumen under anaerobic conditions and results in production of VFA (mainly acetate, propionate, and butyrate). The production of acetate and butyrate releases $\mathrm{H}_{2}$, whereas the production of propionate requires $\mathrm{H}_{2}$. Released $\mathrm{H}_{2}$ is used by methanogenic archaea to reduce carbon dioxide into methane to avoid hydrogen accumulation in the rumen and methane is eliminated mainly through eructation (Demeyer and Fievez, 2000; Moss et al., 2000; Martin et al., 2010). Therefore, $\mathrm{Mp}$ is promoted by production of acetate and butyrate, whereas the propionate and methane synthesis pathways compete for the use of $\mathrm{H}_{2}$ (Moss et al., 2000; Martin et al., 2010). Besides, acetate and butyrate are precursors of de novo synthesis of milk fatty acids (Bernard et al., 2008). Consequently, Chilliard et al. (2009) suggested a direct relationship between $\mathrm{Mp}$ and milk fat composition. Therefore, some previous studies were conducted to investigate raw correlations between milk fatty acids and ruminal methane and to develop equations to predict methane output based on milk fatty acid content (Chilliard et al., 2009; Dijkstra et al., 2011; Mohammed et al., 2011; van Lingen et al., 2014; Williams et al., 2014; Rico et al., 2016).

Generally, positive correlations between ruminal methane on the one hand, and SFA, short-chain fatty acids (SCFA), medium-chain fatty acids (MCFA), or de novo fatty acids on the other hand were reported (Chilliard et al., 2009; Dijkstra et al., 2011; Mohammed et al., 2011; van Lingen et al., 2014; Rico et al., 2016). From experiments using a maize-silage-based diet complemented or not by 3 different physical forms of linseed (crude, extruded, or oil), Chilliard et al. (2009) found high positive correlations between Mp and individual SFA from C6:0 to C16:0 (in \% of total fatty acids; between 0.88 and 0.91). Based on 3 experiments focusing on fat supplementation through 10 dietary treatments, positive correlations between methane yield (i.e., expressed in $\mathrm{g} / \mathrm{kg}$ of DMI) and C8:0, C10:0, C11:0, C14:0 iso, C15:0 iso, C16:0, and C17:0 anteiso (in \% of total fatty acids) were in the range of 0.30 to 0.47 (Dijkstra et al., 2011). Mohammed et al. (2011) supplemented diets of cows with different types of oils (palm, sunflower seed, linseed, or canola seed) and obtained a positive correlation of 0.39 between Mp and sum of SFA (in \% total FAME). van Lingen et al. (2014) performed a meta-analysis (8 experiments and 30 different dietary treatments) to calculate correlations between methane yield (i.e., expressed in g/ $\mathrm{kg}$ of DMI) or methane intensity (i.e., expressed in g/ $\mathrm{kg}$ of fat- and protein-corrected milk) and milk fatty acid profile (in $\mathrm{g} / 100 \mathrm{~g}$ of fatty acids) from data based on cows fed with various diets. Correlations between methane yield and almost all de novo fatty acids were positive. Positive correlations for methane intensity with all SCFA and MCFA were also found, except with C4:0 ( -0.28 for $\mathrm{C} 4: 0$ and between 0.02 and 0.36 for other fatty acids). From experiments using different forage sources (i.e., corn silage, alfalfa silage, barley silage, timothy silage, corn and alfalfa silage, barley and corn silage, or timothy and alfalfa silage), Rico et al. (2016) found positive correlations between Mp and de novo fatty acids (in \% of total fatty acids; 0.34 ). On the contrary, correlations between methane and UFA (Chilliard et al., 2009; Mohammed et al., 2011; van Lingen et al., 2014) or long-chain fatty acids (LCFA; Dijkstra et al., 2011; van Lingen et al., 2014; Rico et al., 2016) were generally negative (from -0.01 to -0.42 ). However, based on data from 8 experiments with forage-based diets supplemented with a large variety of complements, Williams et al. (2014) found, for some of their experiments, correlations between $\mathrm{Mp}$ and $\mathrm{C} 8: 0$ and sum of $\mathrm{C} 18$ that were not consistent with other studies. Finally, Mohammed et al. (2011) and Williams et al. (2014) concluded from their study that milk fatty acid profile only was not appropriate to predict methane reliably.

Overall, these studies used a restricted number of records, even with meta-analyses (less than 300 records). Indeed, obtaining measurements of methane on a large scale remains difficult and expensive, thereby preventing estimations of correlations between methane and milk fatty acids on large data sets and across lactation. Hence, indicator traits or indirect measurements of methane, hereafter called proxies of methane output, that could be measured at a large scale, could be useful to study these correlations (Ellis et al., 2007). Over the last years, in addition to attempting to use fatty acids, other proxies of methane were developed. For example, such proxies can be derived from feed intake and diet composition (e.g., Ellis et al., 2007; de Haas et al., 2011). Another proxy of Mp based on milk mid-infrared (MIR) spectra and lactation stage was developed by Vanlierde et al. (2015). Given that milk MIR spectra are collected routinely through milk-recording schemes, MIR prediction of Mp could be very useful to conduct phenotypic and genetic studies on Mp at large scale.

In addition, previous studies investigating the relationships between milk fatty acids and methane did not consider that these relationships may vary throughout lactation. However, it is known that both milk fatty acid profile and $\mathrm{Mp}$ change over lactation, and that the patterns of milk fatty acid content and of Mp over DIM are different (Bastin et al., 2011; Garnsworthy et al., 2012). Milk fatty acid profile changes both phenotypically and genetically during lactation especially according to the metabolic status of cows (Bastin et 
al., 2011; Gross et al., 2011). Moreover, milk fat composition is strongly influenced by diet composition and intake level (Palmquist et al., 1993), the main drivers of Mp (e.g., Hegarty et al., 2007). Therefore, changes in the relationship between milk fatty acid profile and Mp over lactation should be considered when predicting methane from milk fat composition, to take the evolution of the metabolic status of cows over time into account.

In this context, the goal of this research was to investigate phenotypic and genetic relationships between ruminal methane production and milk fatty acid composition both predicted from milk MIR spectra throughout lactation by using a large data set of Walloon Holstein cows in first lactation. Moreover, the study of the evolution of these correlations across lactation would allow evaluation of the suitability of using milk fatty acid profiles alone to predict ruminal methane.

\section{MATERIALS AND METHODS}

\section{Data Editing}

In the Walloon Region of Belgium, the Walloon Breeding Association (Ciney, Belgium) routinely collects milk samples during farm milk recording since 2007. These milk samples are analyzed using a MIR MilkoScan FT6000 spectrometer (Foss, Hillerød, Denmark) by the milk laboratory 'Comité du Lait' (Battice, Belgium). To predict daily Mp (g/d) of dairy cows from MIR data, a lactation-stage-dependent prediction equation developed by Vanlierde et al. (2015) was applied on spectral data. This prediction equation had a coefficient of determination $\left(\mathbf{R}_{\mathbf{c}}^{\mathbf{2}}\right)$ of 0.75 and a standard error of calibration of $63 \mathrm{~g} / \mathrm{d}$ of methane. Milk fatty acid contents were predicted from MIR data by applying the calibration equations developed by Soyeurt et al. (2011) and updated by Grelet et al. (2014) on MIR spectra. Only individual fatty acids and groups of fatty acids that were well predicted by MIR spectroscopy were studied (i.e., with a ratio between the standard deviation of gas chromatography data used to build the prediction equation and the standard error of cross-validation of the prediction model higher than 3, corresponding to an efficient prediction accuracy; Soyeurt et al., 2011; Grelet et al., 2014). Therefore, individual fatty acids investigated in this study were C4:0, C6:0, C8:0, C10:0, C12:0, C14:0, C16:0, C17:0, C18:0, and C18:1 cis-9. The groups of fatty acids used in this study were SFA, MUFA, UFA, SCFA, MCFA, and LCFA. Data editing was aimed at excluding (1) extreme values of $\mathrm{Mp}$ predictions (i.e., below 150 and above $950 \mathrm{~g} / \mathrm{d}$; Vanlierde et al., 2015) representing only
$0.52 \%$ of the available data; (2) predictions of fatty acid content in milk with values below the first percentile and above the 99th percentile; (3) records outside the range of 5 to 305 DIM; (4) cows with less than 5 testday records; and (5) herds with less than 20 cows with test-day records. After edits, the final data set included 241,236 test-day records for milk fatty acid content and Mp both predicted from MIR spectra from 33,555 Holstein cows in first lactation collected between January 2007 and January 2014 in 626 herds. Pedigree data included 109,975 animals extracted from the database used for the official Walloon genetic evaluation and limited to animals born after 1985 .

\section{Pearson Correlations Between Methane Production and Milk Fatty Acid Contents}

Using raw data, Pearson correlations between MIR predicted Mp (hereafter called predicted Mp), and milk fatty acids were computed using SAS (SAS Institute Inc., Cary, NC). As both types of traits were MIR predicted, the hypothesis that Pearson correlations could be artifacts of the computational methods was tested. To test this hypothesis, Pearson correlations between Mp (based on true measurements, hereafter called true Mp) and MIR predictions of milk fatty acids using 446 measurements from 146 cows were computed. Daily Mp of cows were measured using the sulfur hexafluoride $\left(\mathrm{SF}_{6}\right)$ tracer gas technique (Dehareng et al., 2012). Also, a sample of milk was collected for MIR spectral analyses. Vanlierde et al. (2015) previously provided detailed description of these data. These Pearson correlations were compared with Pearson correlations between $\mathrm{Mp}$ and milk fatty acids both predicted from milk MIR spectra using spectral data from the Walloon milk recording $(\mathrm{n}=241,236)$ or from methane measurements $(\mathrm{n}=446)$.

\section{Model and Genetic Parameters Estimation}

To estimate genetic parameters of studied traits, 16 bivariate (i.e., predicted $\mathrm{Mp}$ and each of the 16 fatty acids traits) random regression test-day mixed models were run. The model was based on the official Walloon genetic evaluation model for production traits (Croquet et al., 2006) and can be written as follows:

$$
\mathbf{y}=\mathbf{X} \boldsymbol{\beta}+\mathbf{Q}(\mathbf{W h}+\mathbf{Z} \mathbf{p}+\mathbf{Z} \mathbf{a})+\mathbf{e},
$$

where $\mathbf{y}$ was the vector of observations (predicted $\mathrm{Mp}$ and individual or groups of milk fatty acids); $\boldsymbol{\beta}$ was the vector of the fixed effects: herd $\times$ test-day, minor lactation stage (classes of 5 DIM), gestation stage $\times$ 
major lactation stage (classes of 122 DIM), and age at calving $\times$ lactation stage $\times$ season of calving; $\mathbf{h}$ was the vector of herd $\times$ year of calving random regression coefficients; $\mathbf{p}$ was the vector of permanent environmental random regression coefficients; a was the vector of additive genetic random regression coefficients; e was the vector of random residual effects; $\mathbf{X}, \mathbf{W}$, and $\mathbf{Z}$ were the incidence matrices assigning observations to effects; and $\mathbf{Q}$ was the covariate matrix for second-order modified Legendre polynomials. Coefficients for polynomials $i_{0}, i_{1}$, and $i_{2}$ were computed as follows (Gengler et al., 1999):

$$
\begin{gathered}
i_{0}=1, \\
i_{1}=\sqrt{3} \times x, \\
i_{2}=\sqrt{5 / 4} \times\left(3 x^{2}-1\right),
\end{gathered}
$$

where $x=-1+2[(\mathrm{DIM}-5) /(365-5)]$. Random effects were considered as correlated between traits, except for residual effects that were considered as independent. (Co)variance components were estimated using the AI-REML algorithm implemented in the AIREMLF90 program (Misztal, 2012).

Daily heritability $\left(h^{2}\right)$ of each trait was estimated at each DIM as follows:

$$
h^{2}=\frac{\sigma_{a}^{2}}{\sigma_{h}^{2}+\sigma_{p}^{2}+\sigma_{a}^{2}+\sigma_{e}^{2}},
$$

where $\sigma_{a}^{2}$ was the genetic additive variance, $\sigma_{h}^{2}$ was the variance of herd $\times$ year of calving, $\sigma_{p}^{2}$ was the permanent environmental variance, and $\sigma_{e}^{2}$ was the residual variance. The variances were obtained from the random regression test-day mixed models. Daily phenotypic and genetic correlations between predicted $\mathrm{Mp}$ and fatty acid traits at DIM $i$ were computed as

$$
r_{M p, F A_{i}}=\frac{\mathbf{t}_{i}{ }^{\prime} \sum_{M p, F A} \mathbf{t}_{i}}{\sqrt{\left(\mathbf{t}^{\prime}{ }^{\prime} \sum_{M p} \mathbf{t}_{i}\right) \times\left(\mathbf{t}_{i}{ }^{\prime} \sum_{F A} \mathbf{t}_{i}\right)}},
$$

where $r_{M p, F A_{i}}$ was the phenotypic or genetic correlation between the methane trait and the fatty acid trait at DIM $i ; \mathbf{t}_{i}$ was the column vector of Legendre polynomial coefficients at DIM $i$ going from 5 to $305 ; \Sigma_{M P, F A}$ was the matrix of phenotypic or genetic covariances between the Mp and the fatty acid trait; and $\Sigma_{M P}$ and $\Sigma_{F A}$ were the phenotypic or genetic variance matrices for predicted Mp and fatty acid traits, respectively.

\section{RESULTS}

\section{Descriptive Statistics and Heritabilities}

Table 1 shows the descriptive statistics of the data set used in this study and average estimated heritabilities of studied traits. Average prediction of Mp was 448 $\mathrm{g} / \mathrm{d}$ with a SD of $71 \mathrm{~g} / \mathrm{d}$. As found by Vanlierde et al. (2015), in the beginning of lactation, these average predictions increased until 100 DIM and decreased afterward (results not shown). Average daily heritability estimate for predicted Mp was moderate (0.25). On average, C16:0 had the highest content in milk of individual fatty acids. Saturated fatty acid and MCFA groups presented the highest contents in milk with regard to saturation of fat and length chain, respectively. Estimates of average daily heritability of studied fatty acids were low-moderate to moderate-high (from 0.15 for C18:1 cis-9 to 0.42 for C14:0). Heritabilities of fatty acids groups were within the same range (from 0.17 for LCFA to 0.41 for MCFA).

\section{Phenotypic and Genetic Correlations Between Methane and De Novo Milk Fatty Acids}

Averaged daily phenotypic and genetic correlations were positive between daily predicted $\mathrm{Mp}$ and all individual SFA as well as between Mp and SFA, SCFA, and MCFA groups (Table 2). However, phenotypic and genetic correlations between some SCFA (i.e., C4:0, C6:0, C8:0, and C10:0) and Mp changed throughout lactation (Figure 1). These fatty acids showed low genetic correlations with predicted $\mathrm{Mp}$ in early lactation (from

Table 1. Mean, SD, and average daily heritability $\left(h^{2}\right)$ with SE of methane production $(\mathrm{g} / \mathrm{d})$ of dairy cows predicted from milk midinfrared spectra and lactation stage and of individual or groups of fatty acid content in milk ( $\mathrm{g} / \mathrm{dL}$ of milk) predicted from milk midinfrared spectra $(\mathrm{n}=241,236)$

\begin{tabular}{lrcc}
\hline Trait & Mean & $\mathrm{SD}$ & $\mathrm{h}^{2}(\mathrm{SE})$ \\
\hline Methane & 448 & 71 & $0.25(0.005)$ \\
C4:0 & 0.106 & 0.017 & $0.31(0.014)$ \\
C6:0 & 0.074 & 0.012 & $0.39(0.016)$ \\
C8:0 & 0.047 & 0.009 & $0.40(0.016)$ \\
C10:0 & 0.110 & 0.027 & $0.40(0.016)$ \\
C12:0 & 0.135 & 0.035 & $0.40(0.016)$ \\
C14:0 & 0.474 & 0.086 & $0.42(0.016)$ \\
C16:0 & 1.261 & 0.266 & $0.38(0.015)$ \\
C17:0 & 0.029 & 0.004 & $0.35(0.015)$ \\
C18:0 & 0.380 & 0.088 & $0.19(0.012)$ \\
C18:1 cis-9 & 0.799 & 0.166 & $0.15(0.011)$ \\
SFA & 2.781 & 0.447 & $0.40(0.016)$ \\
MUFA & 1.112 & 0.200 & $0.19(0.012)$ \\
UFA & 1.263 & 0.221 & $0.20(0.012)$ \\
Short-chain fatty acids & 0.354 & 0.060 & $0.39(0.016)$ \\
Medium-chain fatty acids & 2.187 & 0.404 & $0.41(0.016)$ \\
Long-chain fatty acids & 1.522 & 0.297 & $0.17(0.012)$ \\
\hline
\end{tabular}


-0.07 to 0.22 at 5 DIM) and higher genetic correlation at the end of lactation (from 0.47 to 0.55 at 305 DIM). Genetic correlations between predicted $\mathrm{Mp}$ and SCFA group showed the same pattern throughout lactation (0.10 at 5 DIM and 0.54 at 305 DIM; Figure 2). Phenotypic correlations between predicted $\mathrm{Mp}$ and these individual and group of SCFA had almost the same evolution across DIM as genetic correlations (Figure 1 for individual SCFA and Figure 2 for SCFA group). However, these phenotypic correlations were relatively lower than genetic correlations as shown for average correlations (Table 2). Finally, negative phenotypic and, to a lesser extent, negative genetic correlations were found between $\mathrm{C} 4: 0$ and predicted $\mathrm{Mp}$ at the beginning of lactation ( -0.12 and -0.07 at 5 DIM, respectively). Phenotypic and genetic correlations of C12:0 and C14:0 with predicted Mp showed similar patterns as SCFA across DIM (Figure 1). However, phenotypic correlations between predicted $\mathrm{Mp}$ and some individual fatty acids (i.e., C10:0, C12:0, and C14:0) decreased slightly in early lactation until 100 DIM and increased afterward.

The patterns of phenotypic and genetic correlations between predicted Mp and C16:0 across DIM differed from the general pattern of SCFA group (Figure 3). Overall, these correlations remained stable throughout lactation. Evolution of phenotypic and genetic correlations between predicted Mp and groups of MCFA and SFA throughout lactation was similar to those obtained for C16:0 (Figures 2 and 4).

\section{Phenotypic and Genetic Correlations Between Methane and Other Milk Fatty Acids}

Positive average daily phenotypic and genetic correlations were found between predicted $\mathrm{Mp}$ and $\mathrm{C} 17: 0$ and C18:0 (Table 2). Oleic acid (C18:1 cis-9) and groups of MUFA and UFA showed average phenotypic and genetic correlations with predicted Mp close to zero. Average daily phenotypic correlation between predicted $\mathrm{Mp}$ and LCFA was equal to 0.03 and average genetic correlation was positive (Table 2).

As found for SFA, phenotypic and genetic correlations between predicted $\mathrm{Mp}$ and $\mathrm{C} 17: 0, \mathrm{C} 18: 0$, and $\mathrm{C} 18: 1$ cis-9 obtained in this study varied across DIM. Phenotypic and genetic correlations of C17:0 and C18:0 with predicted Mp were low in early lactation and increased at the beginning of lactation until 100 DIM. Afterward, these correlations decreased except for genetic correlations between $\mathrm{C} 17: 0$ and predicted $\mathrm{Mp}$, which remained stable until the end of lactation (Figure 3). In early lactation, phenotypic and genetic correlations between predicted Mp and C18:1 cis-9 were strongly negative.
Then, these correlations increased until 100 DIM and afterward remained close to zero (Figure 3). Evolution of phenotypic and genetic correlations between predicted Mp and groups of MUFA and UFA showed the same pattern throughout lactation (Figure 4). For the LCFA group, phenotypic and genetic correlations with predicted Mp were strongly negative at the beginning of lactation (phenotypic and genetic correlation of -0.31 and -0.25 at 5 DIM, respectively) and increased until 100 DIM. Afterward, these correlations remained positive and stable but lower than 0.17 (Figure 2).

\section{Pearson Correlations Between Methane and Milk Fatty Acids}

Pearson correlations between MIR predictions of milk fatty acids and $\mathrm{SF}_{6}$ measurements or MIR predictions of $\mathrm{Mp}$ are reported in Table 3. Correlations with predicted Mp (from the spectral data set related to the Walloon spectral database or to the Mp measurements) are in the same range as correlations obtained with true Mp. These Pearson correlations were also in agreement with average daily phenotypic correlations between predicted Mp and milk fatty acids (Table 2) except for correlations with C18:0 (Pearson correlations between -0.19 and -0.12 with predicted or true Mp vs. phenotypic correlation of 0.11 with predicted Mp). However, most of the phenotypic correlations were lower in absolute values compared with Pearson correlations.

Table 2. Averaged daily phenotypic and genetic correlations with $\mathrm{SE}$ between methane production $(\mathrm{g} / \mathrm{d})$ of dairy cows predicted from milk mid-infrared (MIR) spectra and lactation stage and individual or groups of fatty acid content in milk ( $\mathrm{g} / \mathrm{dL}$ of milk) predicted from milk MIR spectra $(\mathrm{n}=241,236)$

\begin{tabular}{lcr}
\hline Fatty acid & $\begin{array}{c}\text { Phenotypic } \\
\text { correlations } \\
\text { (SE) }\end{array}$ & $\begin{array}{c}\text { Genetic } \\
\text { correlations } \\
\text { (SE) }\end{array}$ \\
\hline C4:0 & $0.10(0.022)$ & $0.23(0.036)$ \\
C6:0 & $0.14(0.021)$ & $0.27(0.035)$ \\
C8:0 & $0.15(0.021)$ & $0.29(0.035)$ \\
C10:0 & $0.15(0.026)$ & $0.29(0.035)$ \\
C12:0 & $0.15(0.021)$ & $0.27(0.034)$ \\
C14:0 & $0.14(0.021)$ & $0.24(0.034)$ \\
C16:0 & $0.16(0.021)$ & $0.31(0.035)$ \\
C17:0 & $0.13(0.022)$ & $0.28(0.035)$ \\
C18:0 & $0.11(0.023)$ & $0.32(0.039)$ \\
C18:1 cis-9 & $-0.03(0.024)$ & $-0.02(0.041)$ \\
SFA & $0.16(0.021)$ & $0.30(0.035)$ \\
MUFA & $-0.02(0.024)$ & $0.00(0.039)$ \\
UFA & $-0.01(0.024)$ & $0.04(0.039)$ \\
Short-chain fatty acids & $0.15(0.021)$ & $0.29(0.035)$ \\
Medium-chain fatty acids & $0.14(0.021)$ & $0.25(0.034)$ \\
Long-chain fatty acids & $0.03(0.024)$ & $0.16(0.040)$ \\
\hline
\end{tabular}


VANROBAYS ET AL.
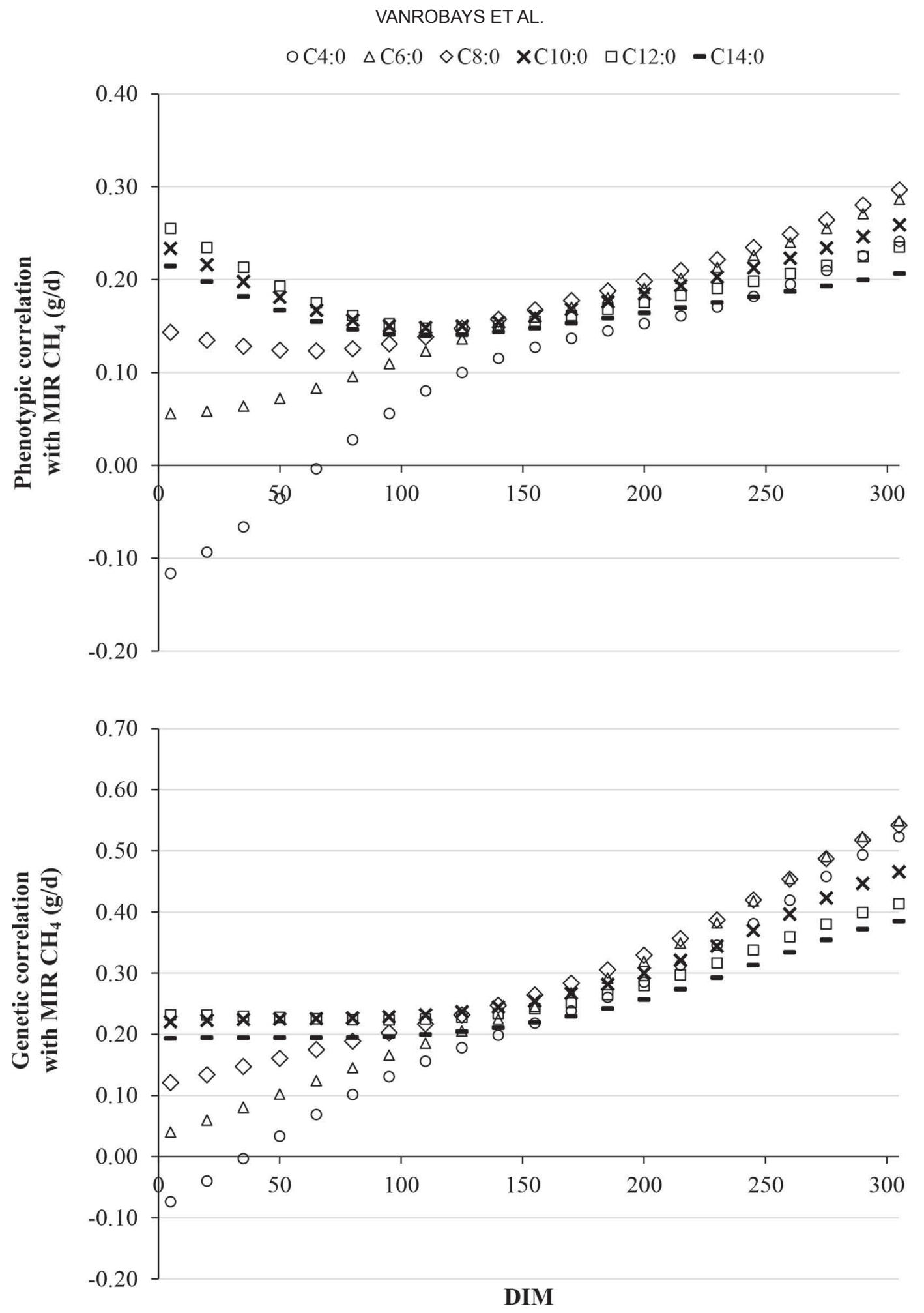

Figure 1. Daily phenotypic and genetic correlations between methane production $(\mathrm{Mp} ; \mathrm{g} / \mathrm{d})$ of dairy cows predicted from milk mid-infrared (MIR) spectra and lactation stage and the content in milk of C4:0, C6:0, C8:0, C10:0, C12:0, and C14:0. 


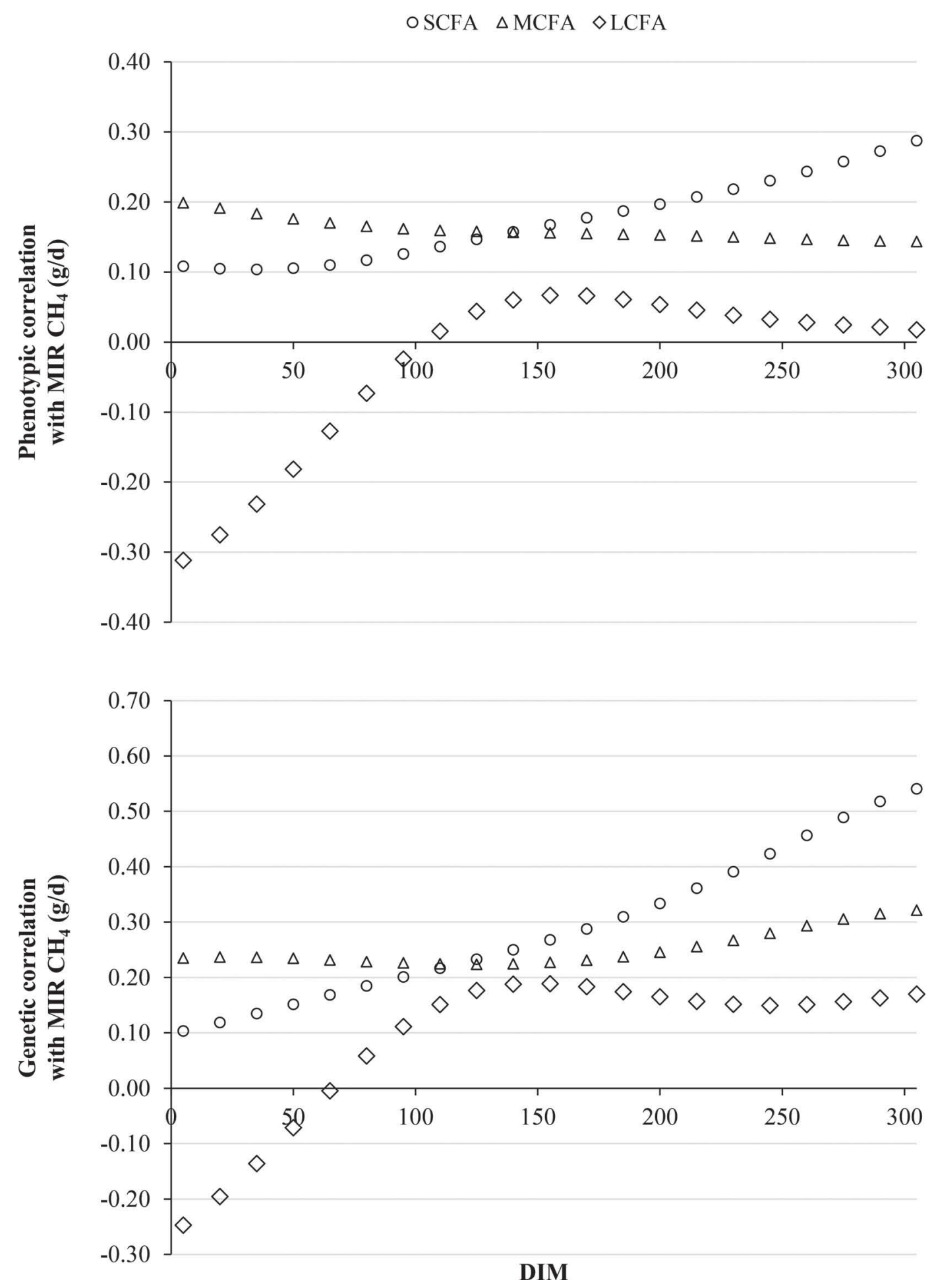

Figure 2. Daily phenotypic and genetic correlations between methane production $(\mathrm{Mp} ; \mathrm{g} / \mathrm{d})$ of dairy cows predicted from milk mid-infrared (MIR) spectra and lactation stage and the content in milk of groups of short-chain (SCFA), medium-chain (MCFA), and long-chain (LCFA) fatty acids predicted from milk MIR spectra. 


\section{DISCUSSION}

The aim of this study was to estimate phenotypic and genetic correlations between $\mathrm{Mp}$ and milk fatty acid content throughout lactation. This research was done using a large data set of primiparous Walloon Holstein cows. Although accuracy of the methane prediction equation was not perfect $\left(\mathrm{R}_{\mathrm{c}}^{2}\right.$ of 0.75$)$, average predic- tions of $\mathrm{Mp}$ over lactation were in agreement with a previous study based on Walloon data using the same equation (Table 1; Vanlierde et al., 2015) and with the literature (e.g., Aguerre et al., 2011; van Zijderveld et al., 2011; Garnsworthy et al., 2012). Values of milk fatty acid predictions were also similar to those obtained in previous Walloon studies (Table 1; e.g., Soyeurt et al., 2007; Bastin et al., 2013).

○ 16 :0 $\Delta \mathrm{C} 17: 0 \diamond \mathrm{C} 18: 0 \quad \times \mathrm{C} 18: 1$ cis-9
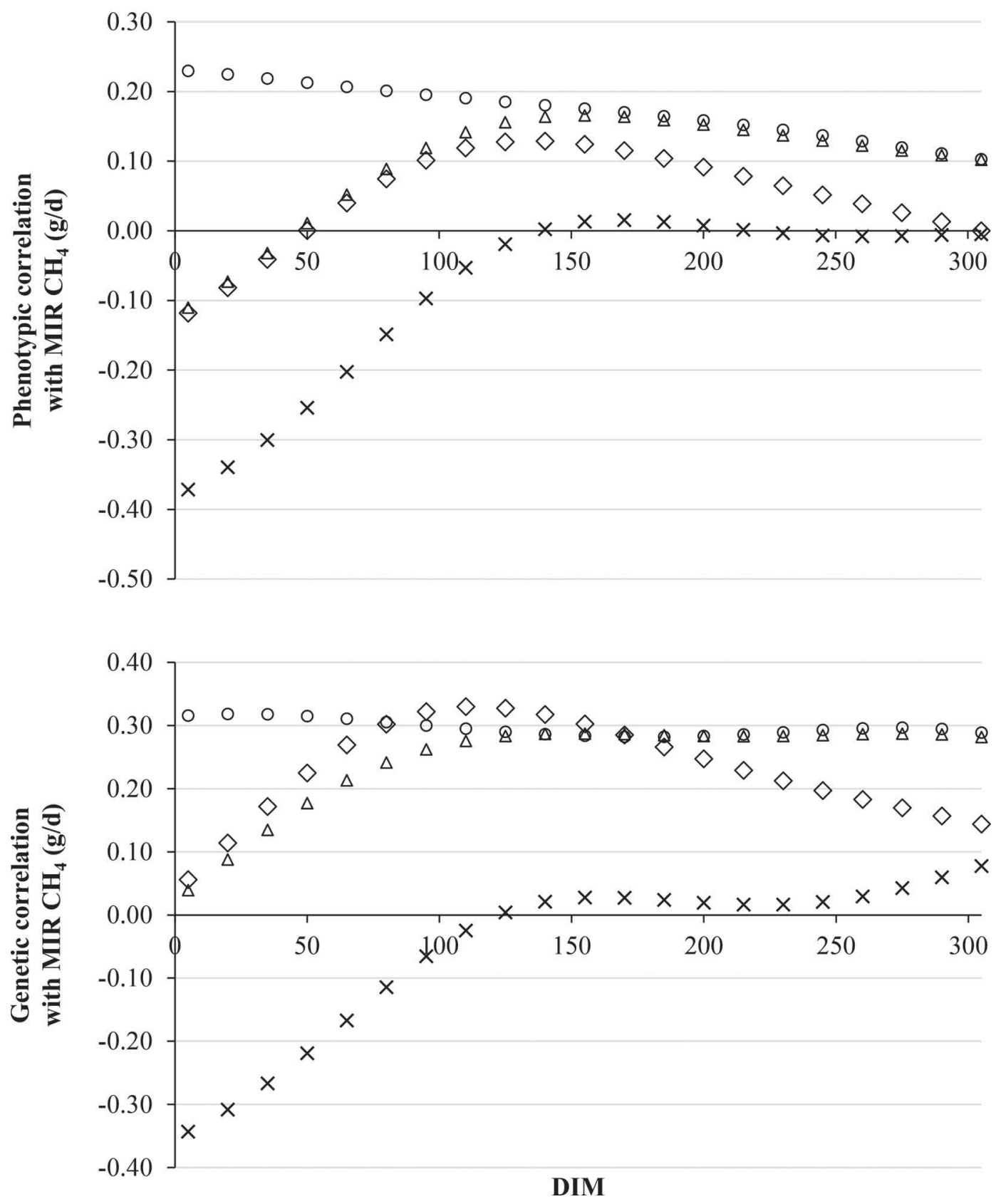

Figure 3. Daily phenotypic and genetic correlations between methane production (Mp;g/d) of dairy cows predicted from milk mid-infrared (MIR) spectra and lactation stage and the content in milk of C16:0, C17:0, C18:0, and C18:1 cis-9. 
The heritability estimate for predicted $\mathrm{Mp}$ was within the range found in the literature for different Mp traits (Table 1). A heritability of 0.21 has been reported by Lassen and Løvendahl (2013) from measurements of methane emissions by Fourier transform infrared analyzer. de Haas et al. (2011) obtained heritability estimates of 0.35 for $\mathrm{Mp}$ estimated indirectly from feed intake. A heritability of 0.13 was obtained by Pickering et al. (2015) from a predicted Mp trait based on milk, BW, feed intake, and BCS. Kandel et al. (2015) reported estimates ranging from 0.29 to 0.35 for predictions of $\mathrm{Mp}$ based on milk fatty acids from equations developed by Chilliard et al. (2009). Regarding fatty acids, values of average daily heritabilities were
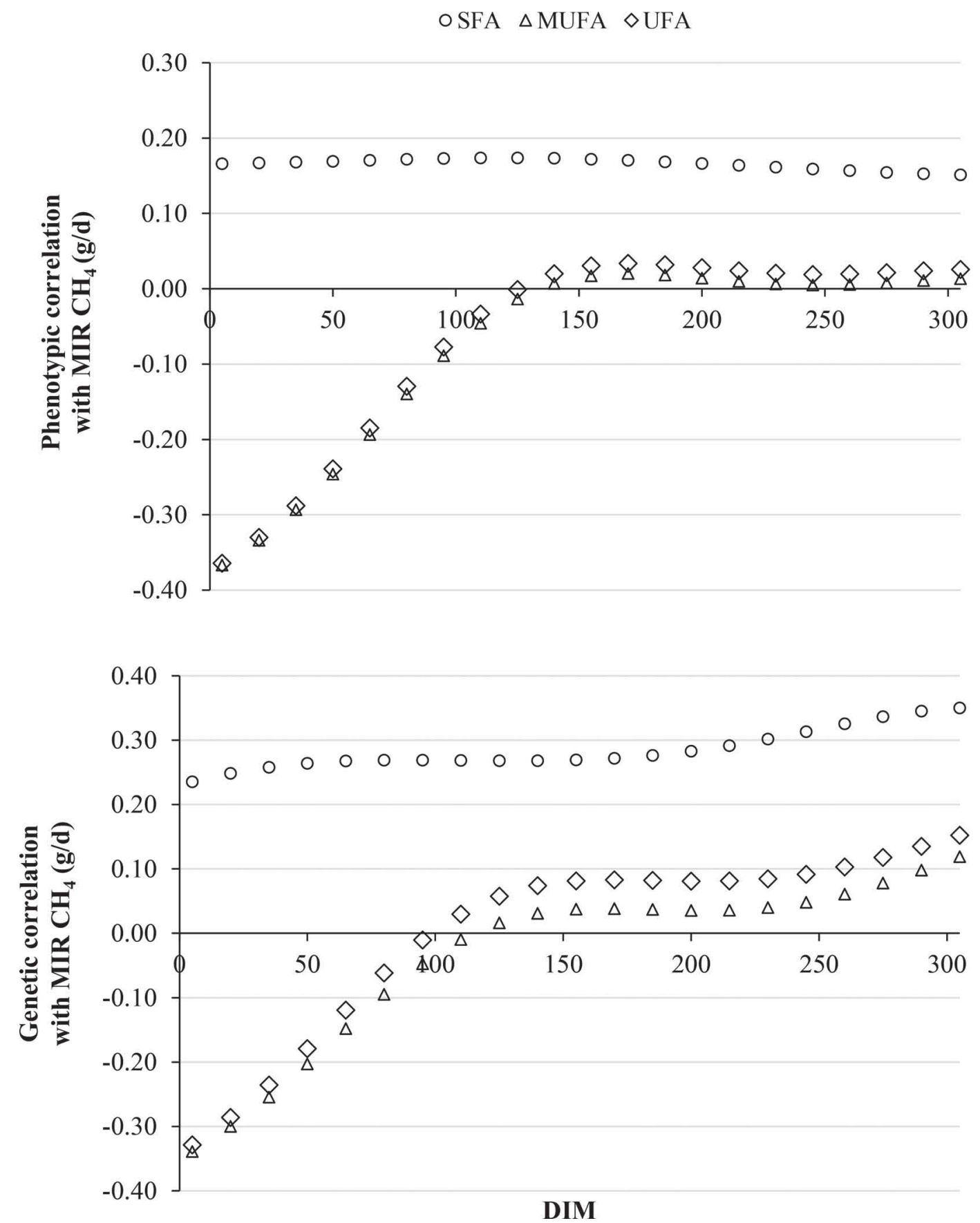

Figure 4. Daily phenotypic and genetic correlations between methane production (Mp; g/d) of dairy cows predicted from milk mid-infrared (MIR) spectra and lactation stage and the content in milk of groups of SFA, MUFA, and UFA predicted from milk MIR spectra. 
in agreement with heritabilities estimated in previous studies based on Walloon data (e.g., Soyeurt et al., 2008; Bastin et al., 2013).

Pearson correlations between milk fatty acids and predicted or true Mp were very similar (Table 3), indicating that the use of predicted $\mathrm{Mp}$ could be a good alternative to estimate correlations between $\mathrm{Mp}$ and milk fatty acids. Nevertheless, correlations with true $\mathrm{Mp}$ were generally lower than those with predicted Mp. Frequency distribution of true Mp being less regular and same method of prediction (i.e., MIR spectra) between predicted $\mathrm{Mp}$ and milk fatty acids could explain these lower correlations (Figure 5). Phenotypic correlations between predicted Mp and fatty acids (Table 2 ) were found to be generally lower in absolute values than Pearson correlations between these traits (Table $3)$, probably because phenotypic correlations were corrected for fixed effects in model [1] (i.e., correcting for similar evolutions and influences of fixed effects). Phenotypic and Pearson correlations between predicted Mp and milk fatty acids obtained in this study (Tables 2 and 3) were lower in absolute values than most of the correlations found in the literature (e.g., Chilliard et al., 2009; Mohammed et al., 2011). Furthermore, Mohammed et al. (2011) reported higher correlations between $\mathrm{Mp}$ and milk fatty acid concentrations within diet than across diets. Therefore, the lower phenotypic correlations obtained in this study compared with the literature could be due to the multi-diet approach, values reported in literature were obtained mostly in single-diet situations, or with only few diets. Given that diets affect ruminal fermentations, their characteristics should be reflected by the type of the associations between Mp and specific milk fatty acids (Rico et al., 2016).

Positive average daily phenotypic correlations were found between Mp and all individual SFA and SFA, SCFA, and MCFA groups (Table 2). Chilliard et al. (2009) found positive correlations between daily $\mathrm{Mp}$ and C4:0, C6:0, C8:0, C10:0, C12:0, C14:0, C16:0, C17:0 and sums of some SFA, SCFA, and MCFA expressed in $\%$ of total fatty acids (from 0.71 to 0.91 ). Positive correlations between Mp and SFA group and C8:0 were reported by Mohammed et al. (2011; 0.39 and 0.37, respectively). Rico et al. (2016) found a positive correlation between $\mathrm{Mp}$ and de novo fatty acids expressed in \% of total fatty acids (0.34). However, these authors found a negative correlation of -0.42 between $\mathrm{Mp}$ and C17:0.

Average daily phenotypic correlations between predicted Mp and C18:1 cis-9 and groups of MUFA and UFA were close to 0 . The group of LCFA showed null phenotypic correlation with predicted Mp (Table 2). However, Chilliard et al. (2009) found a high negative correlation between Mp and the sum of $\mathrm{C} 18$ and $\mathrm{C} 18: 1$ cis-9, all fatty acids being expressed in \% of total fatty acids $(-0.94$ and -0.72 , respectively). Overall, the average daily phenotypic correlations between predicted $\mathrm{Mp}$ and individual and groups of fatty acids were in agreement with the literature.

Table 3. Pearson correlations between individual or groups of fatty acid content in milk ( $\mathrm{g} / \mathrm{dL}$ of milk) predicted from milk mid-infrared (MIR) spectra and methane production ( $\mathrm{Mp} ; \mathrm{g} / \mathrm{d}$ ) of dairy cows measured with the $\mathrm{SF}_{6}$ method $(\mathrm{n}=446)$ or predicted from milk MIR spectra and lactation stage (based on the spectral data set related to the Mp measurements or on the Walloon spectral database; $\mathrm{n}=446$ and $\mathrm{n}=241,236$, respectively)

\begin{tabular}{lcrrr}
\hline & $\begin{array}{c}\text { Correlation with } \\
\text { measured Mp }\end{array}$ & \multicolumn{2}{c}{$\begin{array}{c}\text { Correlation with } \\
\text { predicted Mp }\end{array}$} \\
\cline { 2 - 3 } \cline { 4 - 4 } Fatty acid & $\mathrm{n}=446$ & $\mathrm{n}=446$ & $\mathrm{n}=241,236$ \\
\hline C4:0 & -0.05 & -0.08 & -0.04 \\
C6:0 & 0.19 & 0.20 & 0.20 \\
C8:0 & 0.16 & 0.19 & 0.30 \\
C10:0 & 0.21 & 0.25 & 0.37 \\
C12:0 & 0.21 & 0.25 & 0.39 \\
C14:0 & 0.26 & 0.30 & 0.33 \\
C16:0 & 0.35 & 0.36 & 0.21 \\
C17:0 & 0.08 & 0.09 & 0.13 \\
C18:0 & -0.19 & -0.18 & -0.12 \\
C18:1 cis-9 & -0.18 & -0.21 & -0.34 \\
SFA & 0.25 & 0.27 & 0.24 \\
MUFA & -0.34 & -0.37 & -0.28 \\
UFA & -0.35 & -0.39 & -0.26 \\
Short-chain fatty acids & 0.15 & 0.17 & 0.24 \\
Medium-chain fatty acids & 0.34 & 0.36 & 0.26 \\
Long-chain fatty acids & -0.34 & -0.36 & -0.24 \\
\hline
\end{tabular}




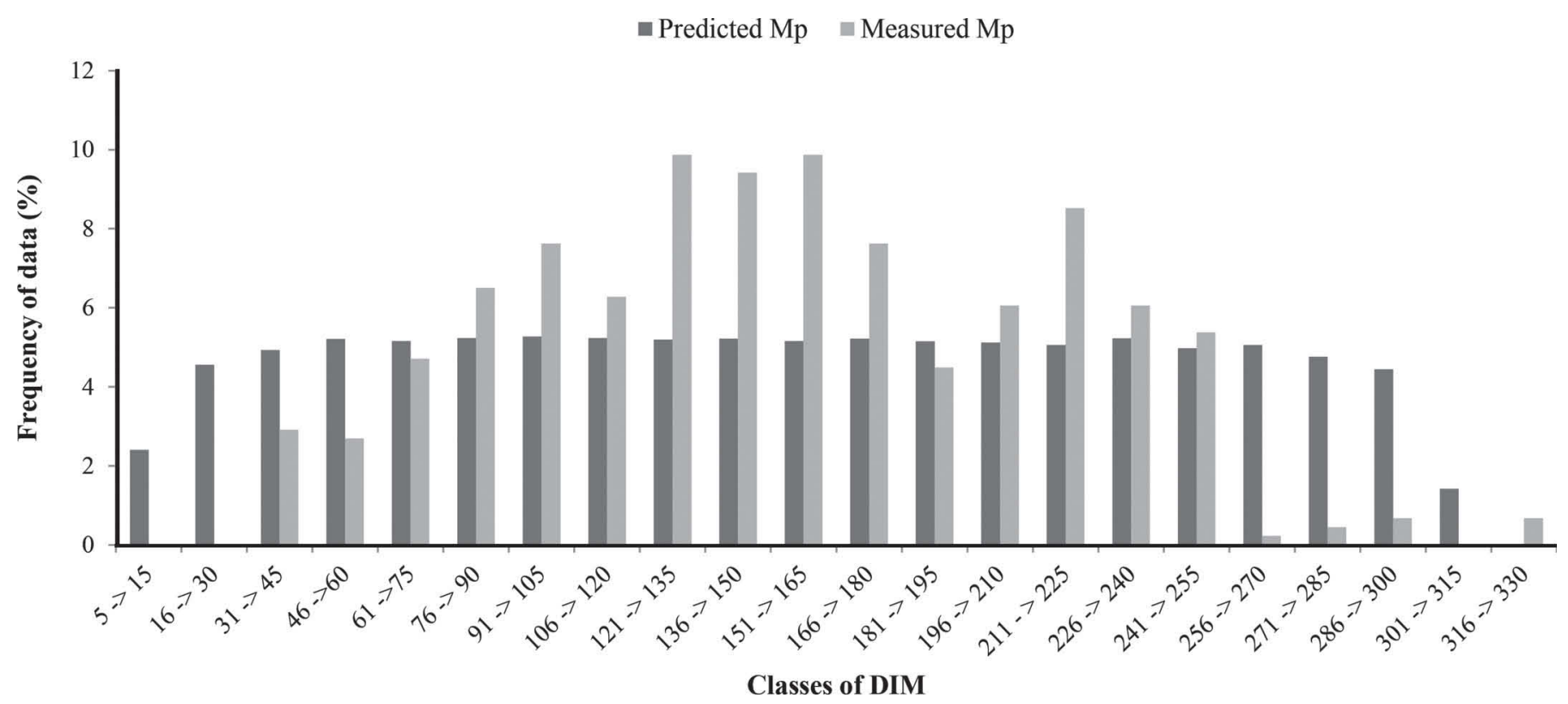

Figure 5. Frequency distribution of data of methane production $(\mathrm{Mp} ; \mathrm{g} / \mathrm{d})$ of dairy cows (1) predicted from milk mid-infrared spectra and lactation stage $(\mathrm{n}=241,236)$ ranging from 5 to 305 DIM and (2) measured with the $\mathrm{SF}_{6}$ method $(\mathrm{n}=446)$ across classes of DIM.

A major part of the individual fatty acids that are positively correlated with daily Mp (Table 2; from C4:0 to $\mathrm{C} 16: 0)$ is derived from de novo synthesis from rumen acetate and $\beta$-hydroxybutyrate in the mammary gland (almost all C4:0 to C14:0 and almost half of C16:0; Grummer, 1991; Bernard et al., 2008; Shingfield et al., 2010). Thus, these positive correlations could be explained by the common biological pathways of acetate, butyrate, and Mp (Chilliard et al., 2009). The evolution of phenotypic and genetic correlations between daily $\mathrm{Mp}$ and individual SCFA (i.e., from C4:0 to C10:0) throughout lactation could be related to the evolution of the energy balance status of cows. At the beginning of lactation, cows are in negative energy balance and some fatty acids are released in milk from body fat mobilization (mainly C16:0, C18:0, and C18:1 cis-9; Palmquist et al., 1993; Chilliard et al., 2000; Gross et al., 2011). Therefore, de novo synthesis of fatty acids in the mammary gland is inhibited because of the high uptake of LCFA (Palmquist et al., 1993). Indeed, in early lactation, milk contains less SCFA and, partly, MCFA than in mid to late lactation (Bastin et al., 2011). At the same time, energy requirements of cows are not met due to insufficient energy intake (van Knegsel et al., 2005). Reduced Mp is expected because feed intake is strongly associated with Mp (Mills et al., 2003). Therefore, low correlations between SCFA and $\mathrm{Mp}$ are expected at the beginning of lactation due to disturbances of their metabolic pathways in early lactation. During mid-late lactation, higher correlations are expected because the cows are generally in positive energy balance. Phenotypic and genetic correlations between predicted Mp and group of SCFA showed a similar evolution throughout lactation as individual SCFA, probably because all fatty acids of this group had the same pattern of correlations across DIM. In early lactation, C4:0 showed negative phenotypic and genetic correlations with predicted Mp. These negative correlations could be explained by the fact that production of $\mathrm{C} 4: 0$ does not require only acetate unlike production of other de novo fatty acids. Indeed, C4:0 could be also produced from BHB originating from the blood (Bernard et al., 2008; van Lingen et al., 2014). In early lactation, when cows are in negative energy balance, synthesis of C4:0 is less inhibited as other de novo fatty acids in the presence of LCFA (Bernard et al., 2008; Shingfield et al., 2010; van Lingen et al., 2014).

Although C16:0 showed positive average daily phenotypic and genetic correlations with predicted $\mathrm{Mp}$, as with other de novo fatty acids, the pattern of correlations between $\mathrm{C} 16: 0$ and $\mathrm{Mp}$ throughout lactation differed from those found for de novo fatty acids. Indeed, these correlations do not have much variation across DIM. This could be explained by the double origin of C16:0 (from de novo synthesis and the blood; Bernard et al., 2008) and because in early lactation, most milk C16:0 comes from mobilization of body fat reserves (Stoop et al., 2009). The patterns of phenotypic and 
genetic correlations observed between predicted $\mathrm{Mp}$ and groups of SFA and SCFA were the same as C16:0 because this fatty acid is the most important in milk (Table 1; Jensen et al., 1991). However, phenotypic and genetic correlations between Mp and some MCFA (i.e., C12:0 and C14:0) showed a similar pattern as SCFA across DIM (Figure 2) because these fatty acids are also produced de novo in the mammary gland from acetate (Grummer, 1991; Bernard et al., 2008; Shingfield et al., 2010).

In early lactation, phenotypic and genetic correlations with predicted Mp were low for C17:0 and C18:0 and negative for C18:1 cis-9. Afterward, these correlations increased until 100 DIM and then remained stable (expected for C18:0; Figure 3). These patterns could be related to origin of these LCFA. Indeed, these fatty acids derived from the blood lipids originating from dietary lipid or from body reserves mobilization (e.g., Bernard et al., 2008). Mobilization of body reserves occurs mainly at the beginning of lactation when cows are in negative energy balance to compensate for the deficiency of nutrients and energy intake, leading to release of adipose fatty acids in milk (Gross et al., 2011). This could explain the negative or zero correlations observed during lactation between predicted $\mathrm{Mp}$ and $\mathrm{C} 17: 0, \mathrm{C} 18: 0$, and $\mathrm{C} 18: 1$ cis-9 because these fatty acids in milk do not originate directly from the diet in early lactation and do not follow the same biological pathways as predicted Mp (Figure 3). With negative energy balance (i.e., in early lactation), the most released fatty acid in milk is C18:1 cis-9 because of large amount of this fatty acid in adipocytes (Rukkwamsuk et al., 2000). This could explain the higher negative phenotypic and genetic correlations observed in early lactation between predicted Mp and C18:1 cis-9 (phenotypic and genetic correlations of -0.37 and -0.34 , respectively) compared with $\mathrm{C} 17: 0$ (phenotypic and genetic correlations of -0.11 and 0.04 , respectively) and C18:0 (phenotypic and genetic correlations of -0.12 and 0.06 , respectively). Phenotypic and genetic correlations of predicted Mp with $\mathrm{C} 18: 1$ cis-9 showed similar patterns across DIM as groups of MUFA, UFA, and LCFA (Figure 4), probably because this fatty acid is predominant in these groups (Table 1).

\section{CONCLUSIONS}

In conclusion, phenotypic and genetic correlations between milk fat composition and milk-based predicted $\mathrm{Mp}$ were found to vary throughout lactation, indicating that inconsistencies among studies reporting correlations between methane and fatty acids might be due to the fact that these correlations vary over lactation. In the present study, correlations between MIR pre- dicted Mp and fatty acids for the whole lactation were validated using measured $\mathrm{SF}_{6}$-based methane data. The pattern of these correlations could be associated with the expected metabolic status of cows following their lactation stage and with the origins of milk fatty acids. Therefore, the use of the milk fatty acid profile alone appears not to be suitable to predict Mp. Further studies are warranted to determine whether insertion of lactation stage information, and therefore the longitudinal nature of their relationship, would improve the prediction equations of methane based on milk fat composition. Also, research is warranted to establish if these improvements of methane predictions from the fatty acid profile could be sufficient and adequate to be used in genetics and management.

\section{ACKNOWLEDGMENTS}

The Ministry of Agriculture of Walloon Region of Belgium (Service Public de Wallonie, Direction générale opérationnelle "Agriculture, Ressources naturelles et Environnement" - DGARNE) through research projects D31-1248 and D31-1304 is acknowledged for its financial support. Jérémie Vandenplas, contributing as a research fellow, Hedi Hammami, as a former postdoctoral fellow, and Nicolas Gengler, as a former senior research associate, acknowledge the support of the National Fund for Scientific Research (Brussels, Belgium). The authors are grateful to the Walloon Breeding Association (Ciney, Belgium) for providing data related to the Walloon milk recording and the milk laboratory 'Comité du Lait' (Battice, Belgium) for providing spectral data. Frédéric Colinet and Hana Bel Mabrouck (University of Liège, Gembloux Agro-Bio Tech, Gembloux, Belgium) are acknowledged for providing predictions from milk spectra. Computational resources have been provided by the Consortium des Équipements de Calcul Intensif (CÉCI), funded by the National Fund for Scientific Research (Brussels, Belgium) under Grant No. 2.5020.11. The National Fund for Scientific Research (Brussels, Belgium) provided also additional support through the FACCE-WB partnership representing the Joint Programming Initiative on Agriculture, Food Security and Climate Change (FACCE-JPI) in the Federation Wallonia-Brussels (WB) of Belgium. Finally, the authors also thank the support of the European Commission under the Seventh Framework Program for the GreenhouseMilk and GplusE projects, Grant Agreements FP7-PEOPLEITN-2008-238562 and FP7-KBBE-613689. The content of the paper reflects only the view of the authors; the European Community is not liable for any use that may be made of the information contained in this publication. 


\section{REFERENCES}

Aguerre, M. J., M. A. Wattiaux, J. M. Powell, G. A. Broderick, and C. Arndt. 2011. Effect of forage-to-concentrate ratio in dairy cow diets on emission of methane, carbon dioxide, and ammonia, lactation performance, and manure excretion. J. Dairy Sci. 94:30813093. http://dx.doi.org/10.3168/jds.2010-4011.

Bastin, C., N. Gengler, and H. Soyeurt. 2011. Phenotypic and genetic variability of production traits and milk fatty acid contents across days in milk for Walloon Holstein first-parity cows. J. Dairy Sci. 94:4152-4163. http://dx.doi.org/10.3168/jds.2010-4108.

Bastin, C., H. Soyeurt, and N. Gengler. 2013. Genetic parameters of milk production traits and fatty acid contents in milk for Holstein cows in parity 1 - 3. J. Anim. Breed. Genet. 130:118-127. http:// dx.doi.org/10.1111/jbg.12010.

Bernard, L., C. Leroux, and Y. Chilliard. 2008. Expression and nutritional regulation of lipogenic genes in the ruminant lactating mammary gland. Adv. Exp. Med. Biol. 606:67-108. http://dx.doi. org/10.1007/978-0-387-74087-4_2.

Chilliard, Y., A. Ferlay, R. M. Mansbridge, and M. Doreau. 2000. Ruminant milk fat plasticity: Nutritional control of saturated, polyunsaturated, trans and conjugated fatty acids. Ann. Zootech. 49:181-205. http://dx.doi.org/10.1051/animres:2000117.

Chilliard, Y., C. Martin, J. Rouel, and M. Doreau. 2009. Milk fatty acids in dairy cows fed whole crude linseed, extruded linseed, or linseed oil, and their relationship with methane output. J. Dairy Sci. 92:5199-5211. http://dx.doi.org/10.3168/jds.2009-2375.

Croquet, C., P. Mayeres, A. Gillon, S. Vanderick, and N. Gengler. 2006. Inbreeding depression for global and partial economic indexes, production, type, and functional traits. J. Dairy Sci. 89:22572267. http://dx.doi.org/10.3168/jds.S0022-0302(06)72297-4.

de Haas, Y., J. J. Windig, M. P. L. Calus, J. Dijkstra, M. de Haan, A. Bannink, and R. F. Veerkamp. 2011. Genetic parameters for predicted methane production and potential for reducing enteric emissions through genomic selection. J. Dairy Sci. 94:6122-6134. http://dx.doi.org/10.3168/jds.2011-4439.

Dehareng, F., C. Delfosse, E. Froidmont, H. Soyeurt, C. Martin, N. Gengler, A. Vanlierde, and P. Dardenne. 2012. Potential use of milk mid-infrared spectra to predict individual methane emission of dairy cows. Animal 6:1694-1701. http://dx.doi.org/10.1017/ S1751731112000456.

Demeyer, D., and V. Fievez. 2000. Ruminants et environnement: la méthanogenèse. Ann. Zootech. 49:95-112. http://dx.doi.org/10.1051/ animres:2000110.

Dijkstra, J., S. M. van Zijderveld, J. A. Apajalahti, A. Bannink, W. J. J. Gerrits, J. R. Newbold, H. B. Perdok, and H. Berends. 2011. Relationships between methane production and milk fatty acid profiles in dairy cattle. Anim. Feed Sci. Technol. 166-167:590-595. http://dx.doi.org/10.1016/j.anifeedsci.2011.04.042.

Ellis, J. L., E. Kebreab, N. E. Odongo, B. W. McBride, E. K. Okine, and J. France. 2007. Prediction of methane production from dairy and beef cattle. J. Dairy Sci. 90:3456-3466. http://dx.doi. org/10.3168/jds.2006-675.

Garnsworthy, P. C., J. Craigon, J. H. Hernandez-Medrano, and N. Saunders. 2012. Variation among individual dairy cows in methane measurements made on farm during milking. J. Dairy Sci. 95:3181-3189. http://dx.doi.org/10.3168/jds.2011-4606.

Gengler, N., A. Tijani, G.R. Wiggans, and I. Misztal. 1999. Estimation of (co)variance function coefficients for test day yield with a expectation-maximization restricted maximum likelihood algorithm. J. Dairy Sci. 82:1849.e1-1849.e23. http://dx.doi.org/10.3168/jds. S0022-0302(99)75417-2.

Gerber, P. J., H. Steinfeld, B. Henderson, A. Mottet, C. Opio, J. Dijkman, A. Falcucci, and G. Tempio. 2013. Tackling Climate Change through Livestock: A Global Assessment of Emissions and Mitigation Opportunities. Food and Agriculture Organization of the United Nations (FAO), Rome, Italy.

Grelet, C., J. A. Fernandez, H. Soyeurt, F. Dehareng, N. Gengler, and P. Dardenne. 2014. Creation of universal MIR calibration by standardization of milk spectra: example of fatty acids. In Book of Abstracts of the 65th Annual Meeting of the European Federation of Animal Science. Wageningen Academic Publishers, Wageningen. 108

Gross, J., H. A. van Dorland, R. M. Bruckmaier, and F. J. Schwarz. 2011. Milk fatty acid profile related to energy balance in dairy cows. J. Dairy Res. 78:479-488. http://dx.doi.org/10.1017/ S0022029911000550.

Grummer, R. R. 1991. Effect of feed on the composition of milk fat. J. Dairy Sci. 74:3244-3257. http://dx.doi.org/10.3168/jds.S00220302(91)78510-X.

Hegarty, R. S., J. P. Goopy, R. M. Herd, and B. McCorkell. 2007. Cattle selected for lower residual feed intake have reduced daily methane production. J. Anim. Sci. 85:1479-1486. http://dx.doi. org/10.2527/jas.2006-236.

Intergovernmental Panel on Climate Change. 2006. IPCC Guidelines for National Greenhouse Gas Inventories, volume 4. Agriculture, forestry and other land use. Accessed Jan. 2016. http://www.ipccnggip.iges.or.jp/public/2006gl/vol4.html.

Jensen, R. G., A. M. Ferris, and C. J. Lammi-Keefe. 1991. The composition of milk fat. J. Dairy Sci. 74:3228-3243. http://dx.doi. org/10.3168/jds.S0022-0302(91)78509-3.

Johnson, K. A., and D. E. Johnson. 1995. Methane emissions from cattle. J. Anim. Sci. 73:2483-2492. doi:http://dx.doi. org/1995.7382483x.

Kandel, P. B., N. Gengler, and H. Soyeurt. 2015. Assessing variability of literature based methane indicator traits in a large dairy cow population. Biotechnol. Agron. Soc. Environ. 19:11-19.

Lassen, J., and P. Løvendahl. 2013. Heritability for enteric methane emission from Danish Holstein cows using a non-invasive FTIR method. Adv. Anim. Biosci. 4:280.

Martin, C., D. P. Morgavi, and M. Doreau. 2010. Methane mitigation in ruminants: From microbe to the farm scale. Animal 4:351-365.

Mills, J. A. N., E. Kebreab, C. M. Yates, L. A. Crompton, S. B. Cammell, M. S. Dhanoa, R. E. Agnew, and J. France. 2003. Alternative approaches to predicting methane emissions from dairy cows. J. Anim. Sci. 81:3141-3150.

Misztal, I. 2012. BLUPF90 Family of Programs. Accessed Aug. 2015. http://nce.ads.uga.edu/wiki/doku.php/.

Mohammed, R., S. M. McGinn, and K. A. Beauchemin. 2011. Prediction of enteric methane output from milk fatty acid concentrations and rumen fermentation parameters in dairy cows fed sunflower, flax, or canola seeds. J. Dairy Sci. 94:6057-6068. http://dx.doi. org/10.3168/jds.2011-4369.

Moss, A. R., J.-P. Jouany, and J. Newbold. 2000. Methane production by ruminants: Its contribution to global warming. Ann. Zootech. 49:231-253. http://dx.doi.org/10.1051/animres:2000119.

Palmquist, D. L., A. Denise Beaulieu, and D. M. Barbano. 1993. Feed and animal factors influencing milk fat composition. J. Dairy Sci. 76:1753-1771. http://dx.doi.org/10.3168/jds.S00220302(93)77508-6.

Pickering, N. K., M. G. G. Chagunda, G. Banos, R. Mrode, J. C. McEwan, and E. Wall. 2015. Genetic parameters for predicted methane production and laser methane detector measurements. J. Anim. Sci. 93:11-20. http://dx.doi.org/10.2527/jas.2014-8302.

Rico, D. E., P. Y. Chouinard, F. Hassanat, C. Benchaar, and R. Gervais. 2016. Prediction of enteric methane emissions from Holstein dairy cows fed various forage sources. Animal 10:203-211. http:// dx.doi.org/10.1017/S1751731115001949.

Rukkwamsuk, T., M. J. H. Geelen, T. A. M. Kruip, and T. Wensing. 2000. Interrelation of fatty acid composition in adipose tissue, serum, and liver of dairy cows during the development of fatty liver postpartum. J. Dairy Sci. 83:52-59. http://dx.doi.org/10.3168/jds. S0022-0302(00)74854-5.

Shingfield, K. J., L. Bernard, C. Leroux, and Y. Chilliard. 2010. Role of trans fatty acids in the nutritional regulation of mammary lipogenesis in ruminants. Animal 4:1140-1166.

Soyeurt, H., P. Dardenne, F. Dehareng, C. Bastin, and N. Gengler. 2008. Genetic parameters of saturated and monounsaturated fatty acid content and the ratio of saturated to unsaturated fatty acids in bovine milk. J. Dairy Sci. 91:3611-3626. http://dx.doi. org/10.3168/jds.2007-0971. 
Soyeurt, H., F. Dehareng, N. Gengler, S. McParland, E. Wall, D. P. Berry, M. Coffey, and P. Dardenne. 2011. Mid-infrared prediction of bovine milk fatty acids across multiple breeds, production systems, and countries. J. Dairy Sci. 94:1657-1667. http://dx.doi. org/10.3168/jds.2010-3408.

Soyeurt, H., A. Gillon, S. Vanderick, P. Mayeres, C. Bertozzi, and N. Gengler. 2007. Estimation of heritability and genetic correlations for the major fatty acids in bovine milk. J. Dairy Sci. 90:44354442. http://dx.doi.org/10.3168/jds.2007-0054.

Stoop, W. M., H. Bovenhuis, J. M. L. Heck, and J. A. M. van Arendonk. 2009. Effect of lactation stage and energy status on milk fat composition of Holstein-Friesian cows. J. Dairy Sci. 92:1469-1478. http://dx.doi.org/10.3168/jds.2008-1468.

van Knegsel, A. T. M., H. van den Brand, J. Dijkstra, S. Tamminga, and B. Kemp. 2005. Effect of dietary energy source on energy balance, production, metabolic disorders and reproduction in lactating dairy cattle. Reprod. Nutr. Dev. 45:665-688. http://dx.doi. org/10.1051/rnd:2005059.

van Lingen, H. J., L. A. Crompton, W. H. Hendriks, C. K. Reynolds, and J. Dijkstra. 2014. Meta-analysis of relationships between en- teric methane yield and milk fatty acid profile in dairy cattle. J Dairy Sci. 97:7115-7132. http://dx.doi.org/10.3168/jds.2014-8268. van Zijderveld, S. M., B. Fonken, J. Dijkstra, W. J. J. Gerrits, H. B. Perdok, W. Fokkink, and J. R. Newbold. 2011. Effects of a combination of feed additives on methane production, diet digestibility, and animal performance in lactating dairy cows. J. Dairy Sci 94:1445-1454. http://dx.doi.org/10.3168/jds.2010-3635.

Vanlierde, A., M.-L. Vanrobays, F. Dehareng, E. Froidmont, H. Soyeurt, S. McParland, E. Lewis, M. H. Deighton, F. Grandl, M. Kreuzer, B. Gredler, P. Dardenne, and N. Gengler. 2015. Hot Topic: Innovative lactation stage dependent prediction of methane emissions from milk mid-infrared spectra. J. Dairy Sci. 98:57405747. http://dx.doi.org/10.3168/jds.2014-8436.

Williams, S. R. O., P. J. Moate, M. H. Deighton, M. C. Hannah, and W. J. Wales. 2014. Methane emissions of dairy cows cannot be predicted by the concentrations of C8:0 and total C18 fatty acids in milk. Anim. Prod. Sci. 54:1757-1761. http://dx.doi.org/10.1071/ AN14292. 